\title{
Mechanical analysis of 20/316L bimetal composite pipe formed by spinning
}

\author{
Wenbin $\mathrm{Xu}^{1,2} \cdot$ Yan $\mathrm{Li}^{1}$
}

Received: 10 October 2021 / Accepted: 20 December 2021

Published online: 20 January 2022

(c) The Author(s) 2022, corrected publication 2022

OPEN

\begin{abstract}
Bimetal composite pipe are widely used in petrochemical industry and other industries due to its good mechanical properties and corrosion resistance. In this paper, the minimum radial rotary pressure $\left(P_{\text {imin }}\right)$ and maximum radial rotary pressure $\left(P_{\text {imax }}\right)$ were obtained by theoretical mechanical calculation, so as to optimize the design of the spinning device. The residual contact pressure was acquired to evaluate the forming quality of the composite pipe. It was found that when the spinning parameters $\left(\delta=0.16 \mathrm{~mm}, \psi=0.4 \mathrm{~mm}, \beta=3.0^{\circ}\right.$ and $\left.f=0.5\right)$, the maximum residual contact pressure was obtained, and the simulated and experimental values were $9.19 \mathrm{MPa}$ and $9.01 \mathrm{MPa}$, respectively. They were close to the theoretical value $(9.67 \mathrm{MPa})$, and the error of these values was about $9 \%$, which proved the accuracy of the theoretical analysis.
\end{abstract}

Keywords Bimetal composite pipe $\cdot$ Spin process $\cdot$ Residual contact stress $\cdot$ Radial rotary pressure

\section{Abbreviations}

$\psi$

The initial gap between the outer wall of inner

pipe and the inner wall of outer pipe

$\delta$

$\beta$

$f$

$r_{\mathrm{oi}}$

$P_{\text {i min }}$

$P_{\text {imax }}$

$P_{\mathrm{rc}}$

$P_{\text {rcmax }}$

$\sigma_{\mathrm{r}}$

$\sigma_{\theta}$

$\sigma_{\text {si }}$

$r_{\mathrm{ii}}$

$\sigma_{\text {so }}$

$r_{\mathrm{oo}}$

$\mathrm{E}_{\mathrm{i}}$

$\mu_{\mathrm{i}}$
$\mathrm{E}_{\mathrm{o}}$

$\mu_{\mathrm{o}}$

Elastic modulus of the material of outer pipe

Poisson's ratio of the material of outer pipe

\section{Introduction}

Bimetal composite pipe is usually made of carbon steel as the material of outer pipe and special material as the material of inner pipe. Bimetal composite pipe fully uses the best physical and chemical properties of the outer pipe and inner pipe [1-3]. It has high strength, excellent corrosion resistance, high-temperature resistance, low-temperature resistance, wear-resistance and other special performance [4-6]. Moreover, the service life of pipe is greatly improved and the cost of pipe is reduced. Therefore, bimetal composite pipe could be widely used in petroleum, chemical and other fields.

The forming technology of metal composite pipe mainly includes hydroforming, drawing forming, explosion forming and spin forming [7-10]. Many scholars and

$\triangle$ Yan Li, a_professorliyan@163.com | 1 School of Mechanical and Electrical Engineering, Anhui Vocational and Technical College, Xinzhan District, Hefei 230011, Anhui, China. ²University of Science and Technology of China, Heifei 230011, Anhui, China. 
research institutions had carried out theoretical, finite element analysis and experimental research on the forming of bimetal composite pipe [11-13]. The influence of die design and material behavior on the extrusion of bimetallic tubes was explored by using finite element and polycrystalline plasticity modeling. The results showed that an extrusion die design proposed that differed from the conventional one was better for reduction in peak forming load satisfying objectives of the traditional design [14]. A forming analysis of clad tube and base tube in spinning process was conducted by numerical simulations and experiments. The results indicated that as the press amount $(\delta)$ increased, the strain of clad tube changed more than base tube and as the feed rate increased, the strain decreased in axial direction and tangential direction but almost unchanged in radial direction [15]. The spin forming parameters of bimetallic composite pipe were optimized by FEM and experiment in my previous research, and the torque and the residual contact pressure were analyzed during forming process. The orthogonal test of four factors and five levels was used to gain the optimal spinning parameters and the effects of factors on analysis indicators under the condition of maximum residual contact pressure and small torque [16]. The bimetallic pipe was manufactured by internal spinning forming technology and via different theories of elastoplastic mechanics were analyzed. The theoretical model of the elastoplastic zone and the elastoplastic boundary position of the outer pipe during the spinning process were proposed and found that the maximum value of the residual contact stress occurred when the spinning pressure unloaded. The validity of the proposed model was verified by finite element simulation and experimentation [17].

Radial rotary pressure is an important parameter for spinning device design, and residual contact pressure is an important parameter for evaluating the forming quality of composite pipe, but there were few researches about on theoretical calculation of residual rotary pressure and residual contact pressure of bimetallic pipe formed by spinning process. In this paper, the radial rotary pressure and residual contact stress of bimetallic pipe were obtained by theoretical mechanical calculation, and the accuracy of theoretical calculation results were verified by FEM and experiment.

\section{Mechanical process of bimetal composite pipe formed by spinning}

The device intended for bimetal composite pipe formed by the spinning process is illustrated in Fig. 1.

Figure 2 shows an analysis of how bimetal composite pipe takes shape under spinning. The curve of $\mathrm{O}-\mathrm{a}-\mathrm{b}$

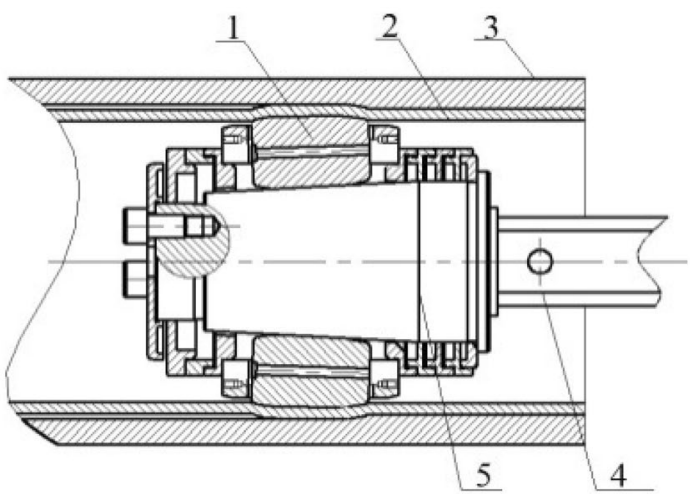

1. Roller 2. Inner pipe 3. Outer pipe 4.Mandrel 5.Rolling element

Fig. 1 The device for bimetal composite pipe formed by spinning process

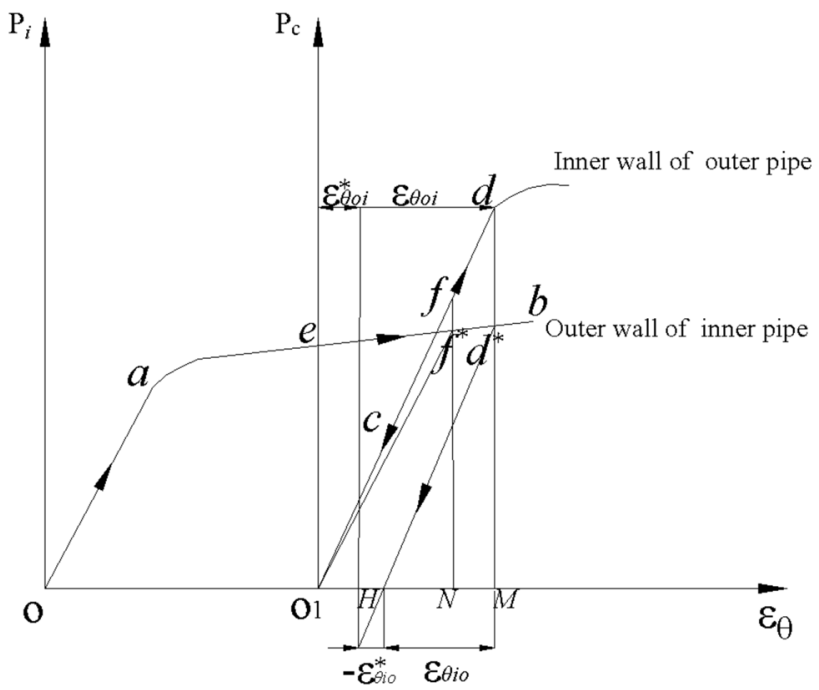

Fig. 2 The spinning forming principle of bimetal composite pipe

reveals the correlation between circumferential strain and radial rotary pressure on the outer wall of the inner pipe. The curve of $\mathrm{O}_{1}-\mathrm{c}-\mathrm{d}$ indicates the relationship between circumferential strain and contact pressure $\left(P_{c}\right)$ in the inner wall of the outer pipe, with the distance of $\mathrm{O}-\mathrm{O}_{1}$ representing the initial gap $(\psi)$ between the outer wall of inner pipe and the inner wall of outer pipe. In the spinning process, elastic deformation (O-a) first occurred to the inner pipe. As rolling continued, the radial rotary pressure increased, while the inner tube shifted from elastic deformation to plastic deformation $(a-b)$. When the radial rotary pressure reached the point $e$ of the curve, the outer wall of the inner pipe started to come into contact with the inner wall of the outer pipe, thus eliminating the gap between the inner pipe and the outer pipe. Meanwhile, the free deformation 
of the inner pipe was limited by the outer pipe, and the contact pressure arose between the outer wall of the inner pipe and the inner wall of the outer pipe. Due to contact pressure, the outer pipe underwent elastic deformation $\left(\mathrm{O}_{1}-\mathrm{d}\right)$, while the outer pipe and inner pipe stuck together tightly. In case that the circumferential strains of the inner and outer tubes could reach point $\mathrm{N}$ under radial rotary pressure, the elastic recovery for the outer wall of the inner pipe and the inner wall of the outer pipe would reach point $\mathrm{O}_{1}$ simultaneously after the release of radial rotary pressure. However, the inner pipe and outer pipe continued sticking together, despite no interlaminar adhesion force (residual contact stress). At this time, the radial rotary pressure corresponding to point $N$ equaled the minimum radial rotary pressure $P_{\mathrm{i} \text { min }}$.

To obtain residual contact stress, it is necessary to increase the radial rotary pressure. When the radial rotary pressure increased to point $d$, the inner wall of the outer pipe reached the elastic limit, which led to the most significant elastic deformation. According to the research results of Dr. Wang, the deformation of outer pipe must be restricted to within the range of elastic deformation, otherwise it would be difficult to ensure safety for the production of composite pipe [7]. Therefore, point $d$ represents the maximum radial rotary pressure $\left(P_{\mathrm{i} \text { max }}\right)$. With radial rotary pressure released at point $d$, the outer wall of the inner pipe and the inner wall of the outer pipe would undergo deformation again, and the elastic recovery of inner wall of outer pipe was more significant as compared to the outer wall of inner pipe. Since the inner diameter of the outer pipe was unlikely to be smaller than the outer diameter of the inner pipe, however, the free elastic recovery was impeded for the inner wall of the outer pipe. Consequently, the residual contact stress $\left(P_{\mathrm{rc}}\right)$ was applied between the inner pipe and the outer pipe, with point $d$ representing the maximum residual contact stress $\left(P_{\mathrm{rc} \mathrm{max}}\right)$. According to the deformation coordination relationship between the inner pipe and the outer pipe, the circumferential strain of the pipes ended up at point $H$, conforming to the following relationship: $\varepsilon_{\theta o i}-\varepsilon_{\theta o i}^{*}=\varepsilon_{\theta i o}-\varepsilon_{\theta i 0^{\circ}}^{*}$.

\section{Mechanical analysis of bimetal composite pipe formed by spinning}

The stress and strain occurring to the inner pipe and outer pipe were highly complex in the spinning process. If all the influencing factors were factored into the theoretical derivation, it would be quite difficult to conduct the mechanical analysis of spinning process and the conclusion may be unreliable. To address the main problem with the spinning process and simplify the calculation under the condition that the calculation results are as accurate as required, the following assumptions were made for the inner pipe and outer pipe. On the one hand, the inner pipe and outer pipe are ideal elastic-plastic materials with sufficient toughness and resistant to low stress brittle fracture. On the other hand, in the spinning process of composite pipe, one end of the pipe is fixed and the other end is free to expand, so that the impact of axial stress is negligible.

The inner pipe suffered plastic deformation under radial rotary pressure and conformed to the equilibrium equation:

$\sigma_{\theta}-\sigma_{r}=r \frac{\mathrm{d} \sigma_{r}}{\mathrm{~d} r}$.

Equation (2) is calculated according to Mises yield failure criterion $\left(\sigma_{\theta}-\sigma_{r}=\frac{2}{\sqrt{3}} \sigma_{\mathrm{si}}\right)$ :

$\mathrm{d} \sigma_{r}=\frac{2}{\sqrt{3}} \sigma_{\mathrm{si}} \frac{\mathrm{d} r}{r}$.

With the boundary condition $r=r_{i j}, \sigma_{r}=-P_{i}$ substituted into Eq. (2), Eqs. (3) and (4) were obtained as follows:

$\sigma_{r}=\frac{2}{\sqrt{3}} \sigma_{\mathrm{si}} \ln \frac{r}{r_{i i}}-P_{\mathrm{i}}$

$\sigma_{\theta}=\frac{2}{\sqrt{3}} \sigma_{\mathrm{si}}+\frac{2}{\sqrt{3}} \sigma_{\mathrm{si}} \ln \frac{r}{r_{i i}}-P_{\mathrm{i}}$

When $P_{\mathrm{i}}=P_{\mathrm{i} \text { max }}$ the contact pressure was equal to $P_{\mathrm{cmax}}$ as shown in Fig. $3 c$.

$\sigma_{\mathrm{so}}=\frac{2 P_{\mathrm{cmax}} r_{\mathrm{oo}}^{2}}{r_{\mathrm{oo}}^{2}-r_{\mathrm{oi}}^{2}} \quad P_{\mathrm{cmax}}=\frac{\sigma_{\mathrm{so}}\left(r_{\mathrm{oo}}^{2}-r_{\mathrm{oi}}^{2}\right)}{2 r_{\mathrm{oo}}^{2}}$

If $\delta=\delta_{\max }$ the stress of the outer wall of the inner pipe was: $\sigma=P_{\text {cmax }}$

$P_{i \max }=\frac{2}{\sqrt{3}} \sigma_{\mathrm{si}} \ln \frac{r_{\mathrm{oi}}+\delta_{\mathrm{max}}}{r_{\mathrm{ii}}}+\frac{\sigma_{\mathrm{so}}\left(r_{\mathrm{oo}}^{2}-r_{\mathrm{oi}}^{2}\right)}{2 r_{\mathrm{oo}}^{2}}$

The circumferential strain $\varepsilon_{\theta o i}$ generated by $P_{c}$ in the inner wall of the outer pipe is expressed as:

$\varepsilon_{\theta \mathrm{oi}}=\frac{2 \pi\left(r_{\mathrm{oi}}+\delta\right)-2 \pi r_{\mathrm{oi}}}{2 \pi r_{\mathrm{oi}}}=\frac{\delta}{r_{\mathrm{oi}}}$

The radial stress $\sigma_{\text {rio }}$ and circumferential stress $\sigma_{\theta \text { io }}$ of the outer wall of the inner pipe are shown in Fig. 3b:

$\left\{\begin{array}{l}\sigma_{\text {rio }}=-P_{\mathrm{c}} \\ \sigma_{\theta \text { io }}=\frac{2}{\sqrt{3}} \sigma_{\mathrm{si}}-P_{\mathrm{c}}\end{array}\right.$ 


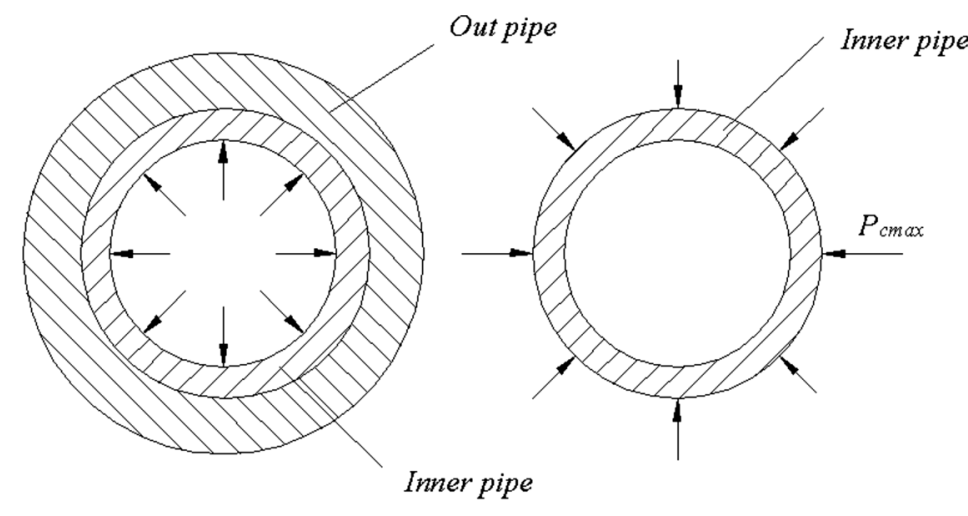

(a)

(b)

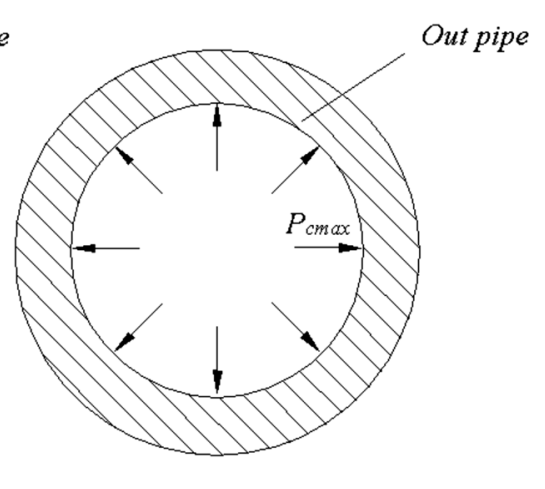

(c)

Fig. 3 Stress state of composite pipes in spin forming

The radial stress $\sigma_{\text {roi }}$ and circumferential stress $\sigma_{\theta \text { oi }}$ of the outer wall of the inner pipe are shown in Fig. $3 \mathrm{c}$ :

$\left\{\begin{array}{l}\sigma_{\text {roi }}=-P_{\mathrm{c}} \\ \sigma_{\theta \text { oi }}=\frac{k^{2}+1}{k^{2}-1} P_{\mathrm{c}}\end{array} \quad k=\frac{r_{\mathrm{oo}}}{r_{\mathrm{oi}}}\right.$

The deformation recurred to the outer wall of the inner pipe during unloading, as shown in Fig. $2\left(d^{*} \sim H\right)$, and the circumferential strain $\varepsilon_{\theta \text { io }}$ resulted from elastic recovery:

$\varepsilon_{\theta \text { io }}=\frac{1}{E_{\mathrm{i}}}\left(\sigma_{\theta \text { iо }}-\mu_{i} \sigma_{\text {rio }}\right)$

With Eq. (8) substituted into Eq. (10):

$\varepsilon_{\theta \text { i }}=\frac{1}{E_{\mathrm{i}}}\left[\frac{2}{\sqrt{3}} \sigma_{\mathrm{si}}+\left(\mu_{\mathrm{i}}-1\right) P_{\mathrm{c}}\right]$

The circumferential strain $\varepsilon_{\theta \text { oi }}$ occurring to the inner wall of the base tube due to the contact stress $P_{c}$ :

$\varepsilon_{\theta \text { oi }}=\frac{1}{E_{\mathrm{o}}}\left(\sigma_{\theta \text { oi }}-\mu_{\mathrm{o}} \sigma_{\mathrm{roi}}\right)$

With Eq. (9) substituted into Eq. (12):

$\varepsilon_{\theta \text { oi }}=\frac{P_{\mathrm{c}}}{E_{\mathrm{o}}}\left(\frac{k^{2}+1}{k^{2}-1}+\mu_{\mathrm{o}}\right)$

Combining Eqs. (7) and (13), it can be obtained that:

$$
\begin{aligned}
& P_{\mathrm{c}}=\frac{E_{\mathrm{o}} \delta}{r_{\mathrm{oi}}\left(\mu_{\mathrm{o}}+\frac{k^{2}+1}{k^{2}-1}\right)} \\
& P_{\mathrm{i}}=\frac{E_{\mathrm{o}} d}{r_{\mathrm{oi}}\left(m_{\mathrm{o}}+\frac{k^{2}+1}{k^{2}-1}\right)}+\frac{2}{\sqrt{3}} s_{\mathrm{si}} \ln \frac{r_{\mathrm{oi}}+\delta}{r_{\mathrm{ii}}}
\end{aligned}
$$

The radial stress $\sigma_{\text {rio }}^{*}$ and circumferential stress $\sigma_{\theta \text { io }}^{*}$ of the outer wall of inner pipe under the action of $P_{\mathrm{rc}}$ are shown in Fig. 4b:

$\left\{\begin{array}{l}\sigma_{r \text { io }}^{*}=-P_{\text {rc }} \\ \sigma_{\theta \text { io }}^{*}=-\frac{k^{2}+1}{k^{2}-1} P_{\mathrm{rc}}\end{array}\right.$

The radial stress $\sigma_{r \text { oi }}^{*}$ and circumferential stress $\sigma_{\theta \text { oi }}^{*}$ of the inner wall of outer pipe under the action of $P_{\mathrm{rc}}$ are shown in Fig. $5 \mathrm{c}$ :

$\left\{\begin{array}{l}\sigma_{\text {roi }}^{*}=P_{\mathrm{rc}} \\ \sigma_{\theta \text { oi }}^{*}=\frac{k^{2}+1}{k^{2}-1} P_{\mathrm{rc}}\end{array}\right.$

The circumferential strain $\varepsilon_{\theta \text { io }}^{*}$ caused by residual contact stress $P_{\mathrm{rc}}$ on the outer wall of the inner pipe:

$\varepsilon_{\theta \text { io }}^{*}=\frac{1}{E_{\mathrm{i}}}\left(\sigma_{\theta \text { io }}^{*}-\mu_{\mathrm{i}} \sigma_{r \text { io }}^{*}\right)$

Combining Eqs. (16) and (18), it can be obtained that:

$\varepsilon_{\theta \text { io }}^{*}=-\frac{P_{\mathrm{rc}}}{E_{\mathrm{i}}}\left(\frac{k^{2}+1}{k^{2}-1}-\mu_{\mathrm{i}}\right)$

The circumferential strain $\varepsilon_{\theta \text { oi }}^{*}$ caused by residual contact stress $P_{\mathrm{rc}}$ on the inner wall of the outer pipe:

$\varepsilon_{\theta \text { oi }}^{*}=\frac{1}{E_{\mathrm{o}}}\left(\sigma_{\theta \text { oi }}^{*}-\mu_{\mathrm{o}} \sigma_{\text {r oi }}^{*}\right)$

Combining Eqs. (17) and (20), it can be obtained that: 


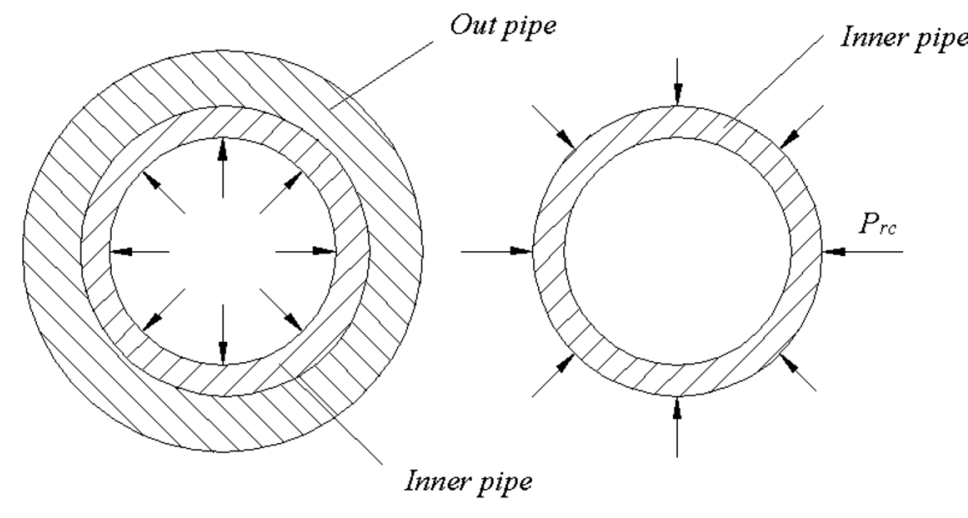

(a) (b)

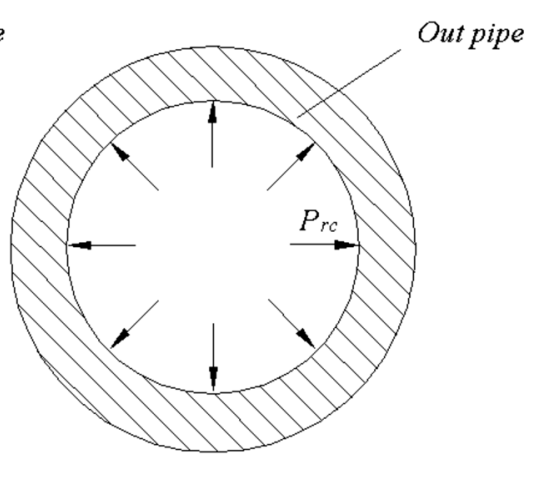

(c)

Fig. 4 Stress state of composite pipes when radial rotary pressure was unloaded

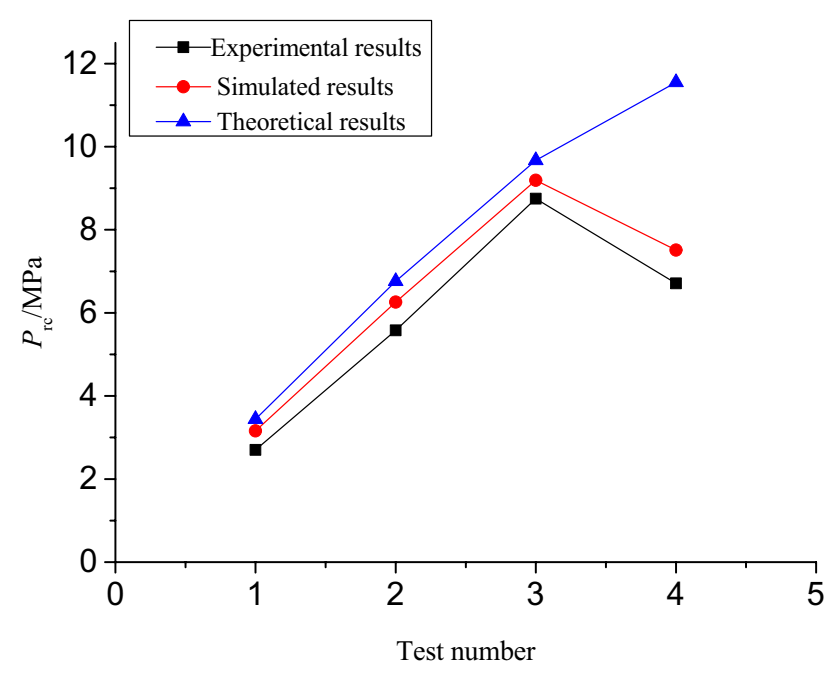

Fig. 5 The comparison of residual contact pressure

$\varepsilon_{\theta \text { oi }}^{*}=\frac{P_{\mathrm{rc}}}{E_{\mathrm{o}}}\left(\mu_{\mathrm{o}}+\frac{k^{2}+1}{k^{2}-1}\right)$

With (11), (13), (19) and (21) substituted into the equation $\left(\varepsilon_{\theta \text { oi }}-\varepsilon_{\theta \text { oi }}^{*}=\varepsilon_{\theta \text { io }}-\varepsilon_{\theta \text { io }}^{*}\right), P_{\text {rc }}$ was obtained as:

$P_{\mathrm{rc}}=\frac{b}{a} P_{\mathrm{c}}-\frac{c}{a}=\frac{b}{a}\left(P_{\mathrm{i}}-\frac{2}{\sqrt{3}} \sigma_{\mathrm{si}} \ln \frac{r_{\mathrm{oi}}+\delta}{r_{\mathrm{ii}}}\right)-\frac{c}{a}$

wh e r e $\quad a=\left(\frac{k^{2}+1}{k^{2}-1}-\mu_{\mathrm{i}}\right) E_{\mathrm{o}}+\left(\frac{k^{2}+1}{k^{2}-1}+\mu_{\mathrm{o}}\right) E_{\mathrm{i}}$; $b=\left(\mu_{\mathrm{o}}+\frac{k^{2}+1}{k^{2}-1}\right) E_{\mathrm{i}}-\left(\mu_{\mathrm{i}}-1\right) E_{\mathrm{o}} ; c=\frac{2}{\sqrt{3}} \sigma_{\mathrm{si}} E_{\mathrm{o}}$.

When $P_{\mathrm{i}}=P_{\mathrm{i} \text { max }}$, the maximum residual contact stress $P_{\text {rc max }}$ was obtained as follows:
Table 1 The spinning process parameters

\begin{tabular}{lllll}
\hline Test number & $\delta(\mathrm{mm})$ & $\psi(\mathrm{mm})$ & $\beta\left(^{\circ}\right)$ & $f$ \\
\hline 1 & 0.10 & 0.35 & 3.5 & 0.35 \\
2 & 0.14 & 0.45 & 3.0 & 0.40 \\
3 & 0.16 & 0.40 & 3.0 & 0.50 \\
4 & 0.18 & 0.50 & 4.5 & 0.40 \\
\hline
\end{tabular}

Where $\beta=$ The centerline of the roller and liner axis Angle; $f=$ Axial feed roller speed/angular velocity

$P_{\mathrm{rcmax}}=\frac{b}{a} \frac{\sigma_{\mathrm{so}}\left(r_{\mathrm{oo}}^{2}-r_{\mathrm{oi}}^{2}\right)}{2 r_{\mathrm{oo}}^{2}}-\frac{c}{a}$

When $P_{\mathrm{rc}}=0$, the minimum radial rotary pressure $P_{\mathrm{i} \text { min }}$ was obtained as follows:

$P_{\mathrm{i} \text { min }}=\frac{2}{\sqrt{3}} \sigma_{\mathrm{si}} \ln \frac{r_{\mathrm{oi}}+\delta}{r_{\mathrm{ii}}}+\frac{c}{b}$

Through the mechanical analysis as to spinning forming of compound pipe, the range of radial spinning pressure was obtained as follows: $\frac{2}{\sqrt{3}} \sigma_{\mathrm{si}} \ln \frac{r_{\mathrm{oi}}+\delta}{r_{\mathrm{ii}}}+\frac{c}{b} \leq P_{\mathrm{i}} \leq \frac{2}{\sqrt{3}} \sigma_{\mathrm{si}} \ln \frac{r_{\mathrm{oi}}+\delta_{\mathrm{max}}}{r_{\mathrm{ii}}}+\frac{\sigma_{\mathrm{so}}\left(r_{\mathrm{oo}}^{2}-r_{\mathrm{oi}}^{2}\right)}{2 r_{\mathrm{oo}}^{2}} \cdot \ln$ addition, the range of residual contact stress was obtained as follows: $0 \leq P_{\mathrm{rc}} \leq \frac{b}{a} \frac{\sigma_{\mathrm{so}}\left(r_{\mathrm{oo}}^{2}-r_{\mathrm{oi}}^{2}\right)}{2 r_{\mathrm{oo}}^{2}}-\frac{c}{a}$.

\section{Finite element analysis and experimental verification}

The numerical simulation and experiment were carried out according to my previous research work [16]. The spinning process parameters of composite pipe are shown in Table 1. The inner pipe was made of $316 \mathrm{~L}$ 
Table 2 Mechanical property of pipe materials

\begin{tabular}{lllll}
\hline Materials & $\begin{array}{l}\text { Yield stress } \\
\sigma_{\mathrm{s}}(\mathrm{MPa})\end{array}$ & $\begin{array}{l}\text { Tensile } \\
\text { stress } \sigma_{\mathrm{b}} \\
(\mathrm{MPa})\end{array}$ & $\begin{array}{l}\text { Elastic } \\
\text { modulus } E \\
(\mathrm{MPa})\end{array}$ & $\begin{array}{l}\text { Poisson's } \\
\text { ratio } \mu\end{array}$ \\
\hline $316 \mathrm{~L}$ & 208 & 600 & 190,000 & 0.26 \\
$\begin{array}{l}20 \text { carbon } \\
\text { steel }\end{array}$ & 325 & 485 & 206,000 & 0.30 \\
\hline
\end{tabular}

stainless steel, and the outer pipe was made of 20 carbon steel. The basic mechanical parameters of the materials are shown in Table 2.

The residual contact stress obtained by theoretical calculation, numerical simulation and experiment is shown in Fig. 5.

As can be seen from Fig. 5, the theoretical results, simulated results and experimental results of residual contact stress were very close to each other, and the deviation between them was about $9 \%$, which was within the engineering acceptable range. The theoretical results were higher than the simulated results, and the simulated results were higher than the experimental results. The reason for this phenomenon was that both the theoretical results and the simulated results assumed that the inner pipe and outer pipe were ideal steel pipes, without considering the material defects of the pipes. However, in the actual spinning process of bimetal composite pipe, the inner wall of inner pipe and outer pipe were not smooth and other defects would cause the reduction in residual contact stress. Therefore, the simulated results and the theoretical results were higher than the experimental results. The theoretical results were calculated based on the ideal elastoplastic model of the inner pipe, while the numerical analysis considered the strain strengthening of the material of the inner pipe to truly simulate the spinning forming of the composite pipe, so the theoretical results were higher than the simulated results. The simulated results and the experimental results increased firstly and then decreased with the increase in $\delta$. The radial rotary pressure increased with the increase in $\delta$, which resulted in the increase in residual contact stress. However, when $\delta$ was greater than $0.16 \mathrm{~mm}$, the outer pipe began to undergo plastic deformation and cannot completely recover its original shape after unloading. The theoretical calculation formula of residual contact stress was only applicable to the elastic deformation of the outer pipe, so the theoretical calculation result was significantly different from the simulation result and experimental result.

\section{Conclusions}

The minimum residual contact stress and the maximum allowable residual contact stress for spinning of bimetal composite pipe were obtained by mechanical analysis, which ensured that the inner pipe and the base pipe were not separated after forming, but also ensured that the inner pipe was not damaged during the forming process. Meanwhile, the residual contact pressure, an important mechanical parameter of metal composite pipe, was acquired.

When the spinning parameters were $\delta=0.16 \mathrm{~mm}$, $\psi=0.4 \mathrm{~mm}, \beta=3.0^{\circ}$ and $f=0.5$, respectively, the maximum residual contact stress was obtained, and the theoretical, simulated and experimental values were $9.67 \mathrm{MPa}$, $9.19 \mathrm{MPa}$ and $9.01 \mathrm{MPa}$, respectively. The experimental and simulated results were consistent with the theoretical analysis results, and the difference between them was about $9 \%$, which effectively proved the accuracy of the theoretical analysis.

Acknowledgements and declaration This work was supported by the Fundamental Research Funds of Anhui Provincial Natural Science Foundation (No. KJ2021 A1452) and Innovation Action Development Foundation (No. XM-06-20). We declared that we did not have any commercial or associative interest that represented a conflict of interest in connection with the submitted manuscript. All data generated or analyzed during this research were included in this submitted manuscript. There were no ethical issues involved in my research. All authors participated in the research and agreed to publish our findings in international journal of advanced manufacturing technology. In this paper, the first author carried out theoretical analysis and FEM on spinning forming of composite pipe, and the corresponding author verified the accuracy of the theoretical calculation results and FEM by experiments

Open Access This article is licensed under a Creative Commons Attribution 4.0 International License, which permits use, sharing, adaptation, distribution and reproduction in any medium or format, as long as you give appropriate credit to the original author(s) and the source, provide a link to the Creative Commons licence, and indicate if changes were made. The images or other third party material in this article are included in the article's Creative Commons licence, unless indicated otherwise in a credit line to the material. If material is not included in the article's Creative Commons licence and your intended use is not permitted by statutory regulation or exceeds the permitted use, you will need to obtain permission directly from the copyright holder. To view a copy of this licence, visit http://creativecommons. org/licenses/by/4.0/.

\section{References}

1. Deng HD, Zeng SP (2014) Corrosion of welded joints of bimetallic composite tube in simulated offshore gas field environment. Anti-Corros Methods Mater 61(6):380-386. https://doi.org/10. 1108/ACMM-08-2013-1295 
2. Bogatov NA, Bogatov AA, Salikhyanov DR (2016) Investigation of simultaneous deformantion of pipes made of dissimilar metals at the production of laminated composite pipe. Izvestia. Ferrous Metall 59(07):437-442. https://doi.org/10.17073/ 0368-0797-2016-7-437-442

3. Akisanya AR, Khan FU, Deans WF (2011) Cold hydraulic expansion of oil well tubulars. Int J Pressure Vessels Pip 88(11):465472. https://doi.org/10.1016/j.ijpvp.2011.08.003

4. Li LY, Xiao J, Han B et al (2020) Welding L415/316L bimetal composite pipe using post-internal-welding process. Trans Indianan Inst Metals 73(03):675-689. https://doi.org/10.1007/ s12666-020-01868-1

5. Khosravifard A, Ebrahimi R (2010) Investigation of parameters affecting interface strength in $\mathrm{Al} / \mathrm{Cu}$ clad bimetal rod extrusion process. Mater Des 31(1):493-499. https://doi.org/10.1016/j. matdes.2009.06.026

6. Zhan M, Yang H, Guo J et al (2015) Review on hot spinning for difficult-to-deform lightweight metals. Trans Nonferrous Met Soc China 25(06):1732-1743. https://doi.org/10.1016/S10036326(15)63778-5

7. Wang XS, Li PN, Wang RZ (2005) Study on hydro-forming technology of manufacturing bimetallic CRA-lined pipe. Int J Mach Tools Manuf 45(04):373-378. https://doi.org/10.1016/j.ijmac htools.2004.09.015

8. Hirama S, Ikeda T, Gondo S (2020) Ball spin forming for flexible and partial diameter reduction in tubes. Metals 10(12):436-441. https://doi.org/10.3390/met10121627

9. Yu Y, Ma HH, Zhao K et al (2017) Study on underwater explosive welding of Al-Steel coaxial pipes. Central Eur J Energ Mater 14(01):251-265. https://doi.org/10.22211/cejem/68696

10. Zhu YX, Chen W, Tu WB (2020) Three-dimensional finite element modeling of rotary-draw bending of copper-titanium composite tube. Int J Adv Manuf Technol 100(5):2377-2389. https://doi. org/10.1007/s00170-019-04781-0
11. Zeng DZ, Deng KH, Lin YH (2014) Theoretical and experimental study of the thermal strength of anticorrosive lined steel pipes. Pet Sci 11(3):417-423. https://doi.org/10.1007/ s12182-014-0356-z

12. Mamalis AG, Petrosyan GL, Manolakos DE et al (2006) Mathematical modelling of plastic deformation processes of bimetallic tubes with porous-internal layer in conical dies. J Mater Process Technol 172(02):243-248. https://doi.org/10.1016/j.jmatprotec. 2005.09.017

13. Tajyar A, Masoumi A (2016) Investigation of mechanical properties of bimetallic square tubes produced by shape rolling of $\mathrm{Al} /$ Cu circular pipes. J Mech Sci Technol 30(9):4299-4306. https:// doi.org/10.1007/s12206-016-0844-8

14. Knezevic $M$, Jahedi $M$, Korkolis YP et al (2014) Material-based design of the extrusion of bimetallic tubes. Comput Mater Sci 95(01):63-73. https://doi.org/10.1016/j.commatsci.2014.07.021

15. Jin K, Yuan QW, Tao J et al (2019) Analysis of the forming characteristics for $\mathrm{Cu} / \mathrm{Al}$ bimetal tubes produced by the spinning process. Int J Adv Manuf Technol 101(4):147-155. https://doi. org/10.1007/s00170-018-2836-6

16. Xu WB, Yang YY, Dai CW et al (2020) Optimization of spinning parameters of 20/316L bimetal composite tube based on orthogonal test. Sci Eng Compos Mater 27(01):272-279. https:// doi.org/10.1515/secm-2020-0026

17. Guo XZ, Yu YH, Tao J et al (2020) Maximum residual contact stress in spinning process of SS304/20 bimetallic pipe. Int J Adv Manuf Technol 106(7):2971-2982. https://doi.org/10.1007/ s00170-019-04774-z

Publisher's Note Springer Nature remains neutral with regard to jurisdictional claims in published maps and institutional affiliations. 